\title{
Spatiotemporal tuning of trace metal mass balance models to quantify global oceanic anoxia for the T-OAE
}

\author{
A. KUNERT ${ }^{1 *}$, B. KENDALL ${ }^{1}$
}

${ }^{1}$ University of Waterloo, Waterloo, ON, Canada

(correspondence: *akunert@uwaterloo.ca)

The Toarcian Oceanic Anoxic Event (T-OAE) was an episode of enhanced climate feedbacks associated with large igneous province (LIP) emplacement. Effects included increased atmosphere/ocean $\mathrm{CO}_{2}$ levels and temperatures, rapid increases in continental weathering, and larger anoxic seafloor areas. To quantify the global anoxic seafloor area leading up to and during the T-OAE, elemental Re and Mo mass balance models [1,2] were applied to black shales of the Gordondale Member (Fernie Formation, British Columbia, Canada) deposited from locally anoxic or euxinic bottom waters. Elemental indicators point to deposition of these black shales on an unrestricted productive continental margin.

These mass balance models were previously developed to observe fluctuations in ocean oxygenation through Earth's history (Archean to Phanerozoic). The early studies made broad assumptions derived from modern environments, including metal source fluxes, sink burial rates, and bulk mass accumulation rates (BMAR). Due to the short duration of the T-OAE, application of mass balance models with tuned source and sink parameters may allow for a more accurate depiction of the ocean redox landscape in the Early Jurassic. The riverine and hydrothermal source fluxes through the Early Jurassic were adjusted from ${ }^{187} \mathrm{Os} /{ }^{188} \mathrm{Os}$ and ${ }^{87} \mathrm{Sr} /{ }^{86} \mathrm{Sr}$ models [3,4], and local BMAR for the 300-500 kyr T-OAE negative carbon isotope excursion (N-CIE) [5] was calculated from core data.

Stratigraphic intervals were delimited from the [Re] and [Mo] trends of locally anoxic and euxinic samples, respectively. Intervals were matched with the most likely source conditions: enhanced hydrothermal flux prior to the NCIE, and a shift to higher riverine flux during the N-CIE. Modelling suggests a maximum expansion of seafloor anoxia from $\sim 1 \%$ global seafloor area during the pre-N-CIE interval to $\sim 6 \%$ global seafloor area immediately preceding and during the lower N-CIE. A minor contraction of anoxic bottom-waters to $\sim 4 \%$ global seafloor area occurs during the upper N-CIE. This spatiotemporal tuning technique can be applied to other times of expanded oceanic anoxia during the Phanerozoic Eon.

[1] Sheen et al. (2018) GCA, 227, 75-95. [2] Reinhard et al. (2013) PNAS, 110, 5357-5362. [3] Them et al. (2017) Nature Sci. Rep., 7, 10p. [4] Jones \& Jenkyns (2001) Am. J. Sci., 301, 112-149. [5] Boulila et al. (2014) EPSL, 386, 98-111. 